\title{
Material Properties and In Vitro Biocompatibility of a Newly Developed Bone Cement
}

\author{
Elke Mitzner, Paco Albertus Hubert Maria Pelt, Christian Mueller, \\ Angela Strohwig ${ }^{\mathrm{a}}$,Wolf-Dieter Mueller ${ }^{\mathrm{b} *}$ \\ ${ }^{\mathrm{a}} \mu$-bond GmbH, D-10117 Berlin, Germany \\ ${ }^{\mathrm{b}}$ Department of Dental Materials and Biomaterial Research, \\ Dental School, "Charité” Medical University of Berlin, \\ D-14197 Berlin, Germany
}

Received: May 27, 2009; Revised: September 4, 2009

\begin{abstract}
In this study mechanical properties and biocompatibility (In Vitro) of a new bone cement were investigated. A new platform technology named COOL is a variable composite of dissolved, chemically modified PMMA and different bioceramics. COOL cures at body temperature via a classical cementation reaction. Compressive strengths ranging from $3.6 \pm 0.8$ to $62.8 \pm 1.3 \mathrm{MPa}$ and bending strengths ranging from $9.9 \pm 2.4$ to $26.4 \pm 3.0 \mathrm{MPa}$ were achieved with different COOL formulations. Porosity varied between 31 and 43\%. Varying the components of each formulation mechanical properties and porosity could be adjusted. In Vitro biocompatibility studies with primary human osteoblasts ( $\mathrm{pHOB}$ ) in direct contact with different COOL formulations, did not reveal any signs of toxicity. In contrast to Refobacin ${ }^{\circledR}$ R, cells incubated with COOL showed similar density, viability and ALP activity compared to control, if specimen were added immediately to the cell monolayer after preparation. In conclusion, COOL has promising mechanical properties in combination with high biocompatibility In Vitro and combines different advantages of both CPCs and PMMA cements by avoiding some of the respective shortcomings.
\end{abstract}

Keywords: bone cement, biomaterial, vertebroplasty, biocompatibility

\section{Introduction}

In modern bone surgery cements are commonly used as bone substitutes and as implant materials to fixate prostheses. Since the development of the first bone cement based on polymethylmethacrylate (PMMA) by Charnley and Smith in the early $1960 \mathrm{~s}^{1,2}$ various bone cements and fillers have been developed,.such as PMMA based cements for orthopedic applications ${ }^{3,4,5}$ bioactive glasses for dental surgery and repair of bone defects ${ }^{6}$ and calcium phosphate cements (CPC) for bone tissue replacement ${ }^{7,8}$. All these biomaterials have their specific properties and have been approved for different application areas. Nevertheless, none of them is without any shortcomings. In case of PMMA cement, radiolucent fibrous tissue is observed at the bone/cement interface, primarily consisting of fibroblasts, macrophages and foreign body giant cells ${ }^{9}$. This fibrous interface is a result of high polymerization temperatures ${ }^{10,11}$ combined with release of toxic methylmethacrylate (MMA) monomers ${ }^{12,13,14}$, both damaging the surrounding tissue. Failure of the bone/cement interface in cemented joint prostheses is the main contributor to implant loosening $^{15}$. Furthermore, PMMA cements have a dense structure, which does not allow bone cells to grow into the cement ${ }^{16}$, and they show inadequate elasticity (E-module) in relation to natural bone, especially to spongiosa ${ }^{17}$. Calcium phosphate cements, however, show good biocompatibility and osteoconduction, but on the other hand they have inappropriate mechanical properties, low biodegradation in vivo, high brittleness, relatively long final setting times and lower flexibility than natural bone $\mathrm{e}^{7,18}$. During the last decade, many research groups tried to improve commercially available biomaterials ${ }^{19,5,20}$, but no breakthrough has been achieved so far.
The aim of the present studies was to investigate mechanical properties and In Vitro biocompatibility of a newly developed biomaterial, a platform technology named COOL. COOL is a variable composition of commonly accepted bioceramics and chemically modified PMMA. This technology is reported to combine the advantages as release of inorganic components and high mechanical strength by avoiding the disadvantages such as high temperature, monomer release and/or low bending strength. Furthermore, COOL is said to fill the gap between CPCs and PMMA based cements.

\section{Materials and Methods}

\subsection{Composition of materials}

COOL Bone Cement (COOL) is a two component system of powder and liquid ${ }^{21}$. The powder component contains several bioceramics: the bioresorbable glass ceramic GB14 $4^{22,23}$ tetra calcium phosphate (TETRA), a mixture of fluorapatite (FA) and calcium zirconium phosphate $(\mathrm{CZP})^{24}$ and zinc oxide $(\mathrm{ZnO})$. All bioceramics have defined particle sizes in the range of 2 to $200 \mu \mathrm{m}$. COOL contains 50 to $70 \mathrm{wt}$. (\%) of inorganic components. The liquid contains acidmodified polymethylmethacrylate (PMMA) dissolved in a mixture of ethylacetoacetate and ethanol $(1: 1)$. The powder component was sterilized by heat sterilization for 2 hours at $200^{\circ} \mathrm{C}$, whereas no sterilisation of the liquid component is required because of the solvent's composition. Tested formulations of COOL are listed in Table 1.

Refobacin ${ }^{\circledR}$ Bone Cement R (Biomet, Berlin, Germany) was used as a reference because of its broad application and acceptance as gold standard. This bone cement is a mixture of a powder containing PMMA, zirconium dioxide, benzoyl peroxide, gentamycin sulphate 
Table 1. Composition of different COOL formulations

\begin{tabular}{|c|c|c|}
\hline COOL formulation & Variation compared to standard formulation & Composition wt. (\%) ceramic powder \\
\hline $\mathrm{A}$ & standard & $\begin{array}{c}\text { GB14, TETRA,FA/CZP, } \mathrm{ZnO} \\
30 \%, 30 \%, 35 \%, 5 \%\end{array}$ \\
\hline $\mathrm{A} / 2$ & standard without $\mathrm{ZnO}$ & $\begin{array}{c}\text { GB14, TETRA, FA/CZP } \\
30 \%, 30 \%, 40 \%\end{array}$ \\
\hline $\mathrm{B}$ & substitution of FA/CZP by CZP & $\begin{array}{c}\text { GB14, TETRA, CZP, } \mathrm{ZnO} \\
30 \%, 30 \%, 35 \%, 5 \%\end{array}$ \\
\hline $\mathrm{C}$ & substitution of $40 \mathrm{wt}$ ( $\%$ ) GB14 by TETRA & $\begin{array}{c}\text { GB14, TETRA, FA/CZP, } \mathrm{ZnO} \\
18 \%, 42 \%, 35 \%, 5 \%\end{array}$ \\
\hline $\mathrm{D}$ & substitution of 40 wt. (\%) GB14 by TETRA and FA/CZP & $\begin{array}{c}\text { GB14, TETRA, FA/CZP, ZnO } \\
18 \%, 36 \%, 41 \%, 5 \%\end{array}$ \\
\hline $\mathrm{E}$ & substitution of 40 wt. (\%) GB14 by FA/CZP & $\begin{array}{c}\text { GB14, TETRA, FA/CZP, } \mathrm{ZnO} \\
18 \%, 30 \%, 47 \%, 5 \%\end{array}$ \\
\hline
\end{tabular}

$\mathrm{FA}=$ fluor apatite; $\mathrm{GB} 14=$ the resorbable glass ceramic; TETRA $=$ tetra calcium phosphate, $\mathrm{CZP}=$ calcium-zirconium-phosphate, $\mathrm{ZnO}=$ zinc oxide.

and a solution consisting of methylmethacrylate and N,N-dimethylp-toluidine.

\subsection{Mechanical strength}

Determination of four point bending strength was carried out according to DIN standard 53435 utilizing a Dynstat device. Specimens with a dimension of $15 \times 10 \times 2$ mm were manufactured using Teflon ${ }^{\circledR}$ moulds. Series of $\geq 10$ specimens per formulation were investigated after 24 hours of storage in water at $37^{\circ} \mathrm{C}$ followed by 24 hours of drying at room temperature. The comparability of four point bending test according to DIN 53435 and three point bending test after ISO 5833 was demonstrated by Kuehn ${ }^{3}$.

Compressive strength was measured according to ISO standard 5833. Specimens with $6 \mathrm{~mm}$ in diameter and $12 \mathrm{~mm}$ in height were manufactured using Teflon moulds. After storage in water at $37^{\circ} \mathrm{C}$ for 24 hours and subsequent drying for 24 hours, $\geq 5$ specimens were measured for each formulation using the universal test device ZWICK 010 (Ulm, Germany) with a traverse speed of $21 \mathrm{~mm} / \mathrm{min}$.

Differing from the usual setting procedures described above test specimens of the standard formulation were also stored in air at $37^{\circ} \mathrm{C}$ for up to 10 days and in water at $37^{\circ} \mathrm{C}$ with 24 hours drying period for up to 7 days.

\subsection{Setting behavior}

The initial time of setting was determined using a Gillmore needle according to ASTM standard C 266-04. Cement was poured into moulds with $11 \mathrm{~mm}$ in diameter and $14 \mathrm{~mm}$ in height and surface was flattened. Moulds were stored in water at $37^{\circ} \mathrm{C}$. Time measurement started when PMMA solution contacted the ceramic powder. For every collection of data 3 specimens with maximum 6 indentations were used.

\subsection{Porosity}

For determination of pore proportion, density of selected examples was measured using the helium pycnometer AccuPyc 1330 (Micromeritics, Mönchengladbach, Germany). After determining volume (V) and weight of the specimens, they were grinded with a ball mill and 2 to $3 \mathrm{~g}$ of the powder were used for investigation. Powder volume was calculated from the determined density and the weight of the powders.

Porosity was calculated using the formula:

$$
\text { Porosity }=\frac{V_{\text {specimen }}-V_{\text {powder }}}{V_{\text {specimen }}} \times 100 \%
$$

\subsection{Scanning electron microscopy (SEM)}

SEM micrographs (Maxim, Cambridge,UK) were performed under low vacuum conditions ( $10 \mathrm{mbar}$ ) with $20 \mathrm{kV}$ acceleration energy of primary electrons using back scattered imaging mode. Braking edges of COOL specimens, which were used for determining bending strength, were photographed for analyzing pore structure.

\section{6. $X$-ray opacity}

Using the X-ray device TransX (Schütz-Dental, Rosbach, Germany), COOL formulation A was investigated for radiopacity in relation to 2 different reference materials: Refobacin ${ }^{\circledR} \mathrm{R}$ bone cement containing zirconium dioxide $\left(\mathrm{ZrO}_{2}\right)$ and a titan implant sample with $8 \mathrm{~mm}$ in diameter and $2 \mathrm{~mm}$ in thickness, as representative for metallic implant materials.

\subsection{In Vitro cell culture and experimental procedure}

In Vitro biocompatibility testing of COOL formulation A was examined according to ISO and DIN 10993-5 in a culture model of primary human osteoblasts ( $\mathrm{pHOB}$ ). $\mathrm{pHOB}$ cells, collected from bone samples of a 66 year old female (donor 1) and a 72 year old male (donor 2), both undergoing total hip surgery, were purchased from Provitro (Berlin, Germany). Osteoblasts from both donors were characterized for osteocalcin expression. pHOB cells from each donor were cultured separately on 12-well plates at a concentration of $5 \times 10^{4}$ per well in Osteomed Growth Medium supplemented with $4 \mathrm{mM}$ L-glutamine, $50 \mu \mathrm{g} . \mathrm{mL}^{-1}$ gentamycin, $50 \mathrm{ng} \cdot \mathrm{mL}^{-1}$ amphotericin B, $20 \mathrm{mM}$ HEPES and $10 \%$ heat-inactivated fetal calf serum (purchased as complete medium from Provitro, Berlin, Germany). Cultures were incubated in a humidified atmosphere containing $5 \%$ $\mathrm{CO}_{2}$ at $37{ }^{\circ} \mathrm{C}$ with replacement of medium every 2 to 3 days. After allowing the cells to attach to the surface of the wells for 24 hours, bone cement specimens with a surface area of $0.38 \mathrm{~cm}^{2}$ were prepared and added to the cell monolayer either directly after preparation or after 5 and 24 hours of setting in culture medium at $37^{\circ} \mathrm{C}$. At day 7 of culture the medium was supplemented with $10 \mathrm{nM}$ dexamethasone, $5 \times 10^{-8} \mathrm{M} 1,25(\mathrm{OH})_{2} \mathrm{D}_{3}, 50 \mu \mathrm{g} . \mathrm{mL}^{-1} \mathrm{~L}$-ascorbic acid, $10 \mathrm{mM}$ B-glycerolphosphate and $1.5 \mathrm{mM} \mathrm{CaCl}_{2}$ in order to induce osteogenic differentiation. All osteogenic supplements were purchased from Sigma-Aldrich (Deisenhofen, Germany).

\subsection{Cell morphology and viability}

During the entire culturing period, morphology and density of pHOB cells were observed by light microscopy and photographed. 
For determination of cell viability/proliferation Alamarblue ${ }^{\mathrm{TM}}$ assay (Biozol, Eching, Germany) was performed every 2 to 3 days according to the manufacturer's instructions. Briefly, $1 \mathrm{~mL}$ of culture medium together with $100 \mu \mathrm{L}$ of Alamarblue ${ }^{\mathrm{TM}}$ reagent were added to each well and the cells were incubated in this medium/Alamarblue ${ }^{\mathrm{TM}} \mathrm{mix}$ under humidified $5 \% \mathrm{CO}_{2}$ conditions at $37{ }^{\circ} \mathrm{C}$. After 3 hoursours of incubation, absorbance was analyzed spectrophotometrically at $570 \mathrm{~nm}$ with $595 \mathrm{~nm}$ as a reference.

\subsection{Alkaline phosphatase (ALP) activity}

ALP activity was assessed in cell lysates by determining the release of p-nitrophenol (PNP) from p-nitrophenyl phosphate (PNPP) using the Phosphate Substrate Kit from Perbio Science (Bonn, Germany). The substrate solution contained $1 \mathrm{mg} \cdot \mathrm{mL}^{-1}$ of PNPP dissolved in $1 \mathrm{M}$ diethylamine substrate buffer ( $\mathrm{pH}$ 9.8). After an incubation period of at least 20 minutes (which was in the linear range) at $37{ }^{\circ} \mathrm{C}$, the reaction (volume $110 \mu \mathrm{L}$ ) was stopped with $50 \mu \mathrm{L} 2 \mathrm{~N} \mathrm{NaOH}$. Results of ALP activity were extrapolated from a

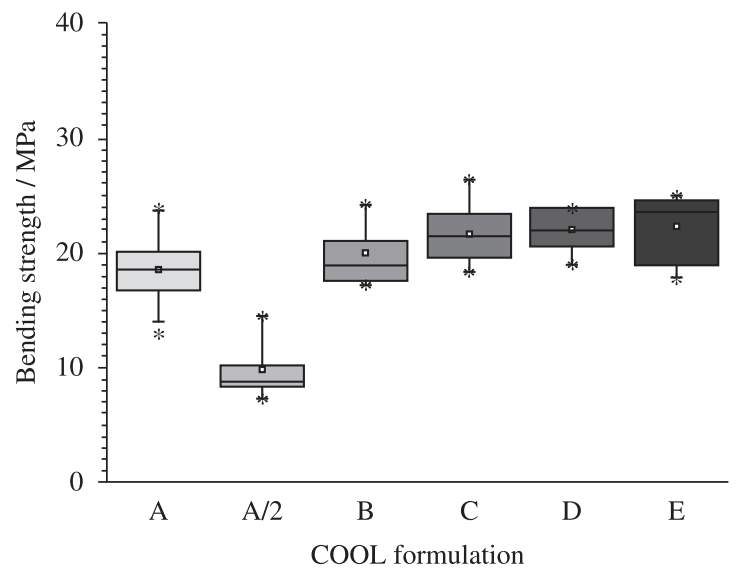

Figure 1. 4- point- bending strength according to DIN 53435 of different COOL formulations (mean $\pm \mathrm{SD}, \mathrm{n}=6$ ) measured after 48 hours ( 24 hours in $\mathrm{H}_{2} \mathrm{O}$ at $37^{\circ} \mathrm{C}, 24$ hours in air at $21^{\circ} \mathrm{C}$ ). Statistical significant differences are marked with $*$ for $\mathrm{p}<0.05$

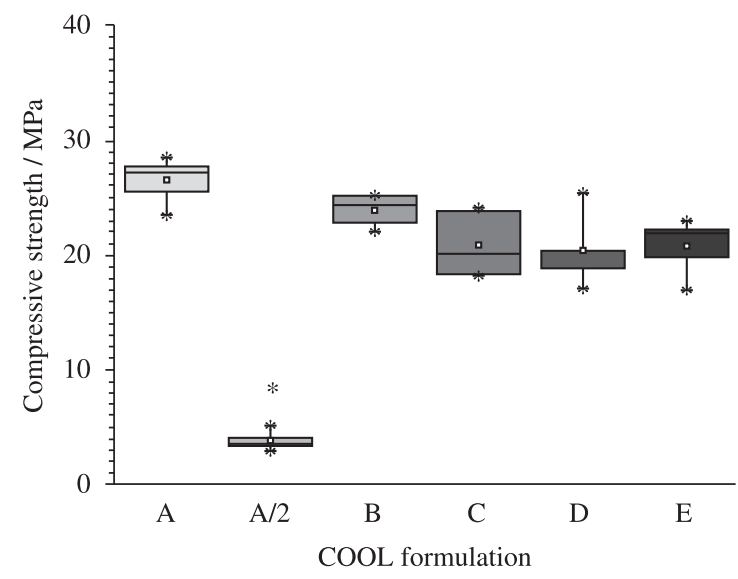

Figure 2 . Compressive strength according to ISO 5833 of different COOL formulations (mean $\pm \mathrm{SD}, \mathrm{n}=6$ ) measured after 48 hours ( 24 hours in $\mathrm{H}_{2} \mathrm{O}$ at $37^{\circ} \mathrm{C}, 24$ hours in air at $21^{\circ} \mathrm{C}$ ). Statistical significant differences are marked with * for $\mathrm{p}<0.05$ standard curve of PNP (Sigma-Aldrich, Deisenhofen, Germany) and related to cell viability.

\subsection{Statistics}

All the data are expressed as means \pm SD. Statistical differences were analyzed using one-way analysis of variance (ANOVA). $P$ values $<0.05$ were considered statistically significant.

\section{Results}

\subsection{Mechanical strength}

Depending on the formulation of the cement bending strengths from $9.9 \pm 2.4$ to $26.4 \pm 3.0 \mathrm{MPa}$ and compressive strengths from $3.6 \pm 0.8$ to $26.2 \pm 1.8 \mathrm{MPa}$ were achieved 48 hours after mixing. Bending strength (Figure 1) and compressive strength (Figure 2) increased significantly if $\mathrm{ZnO}$ (up to $7 \%$ ) was added to the different formulations. COOL formulation B contained CZP instead of CZP/

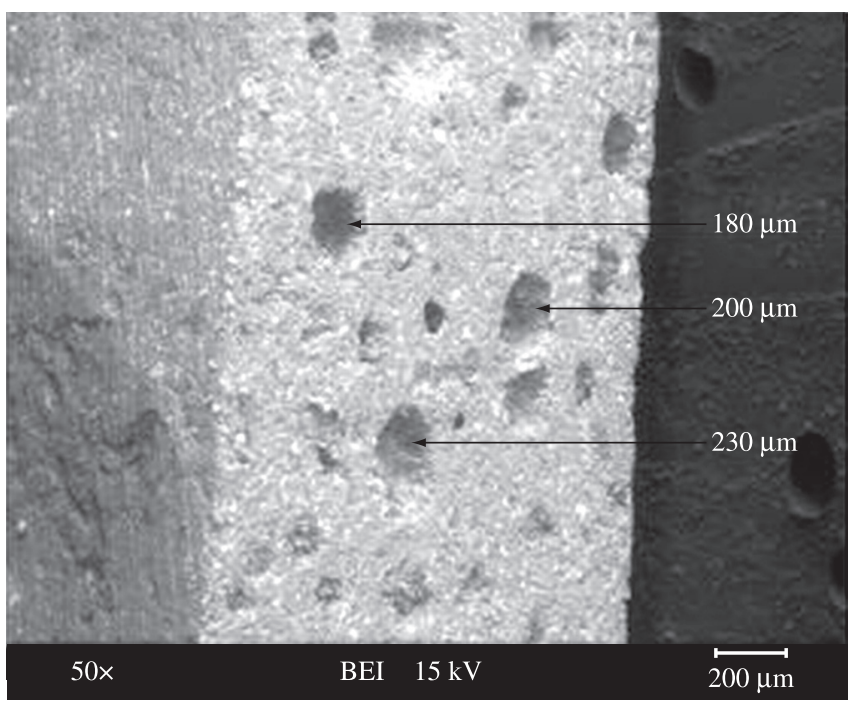

(a)

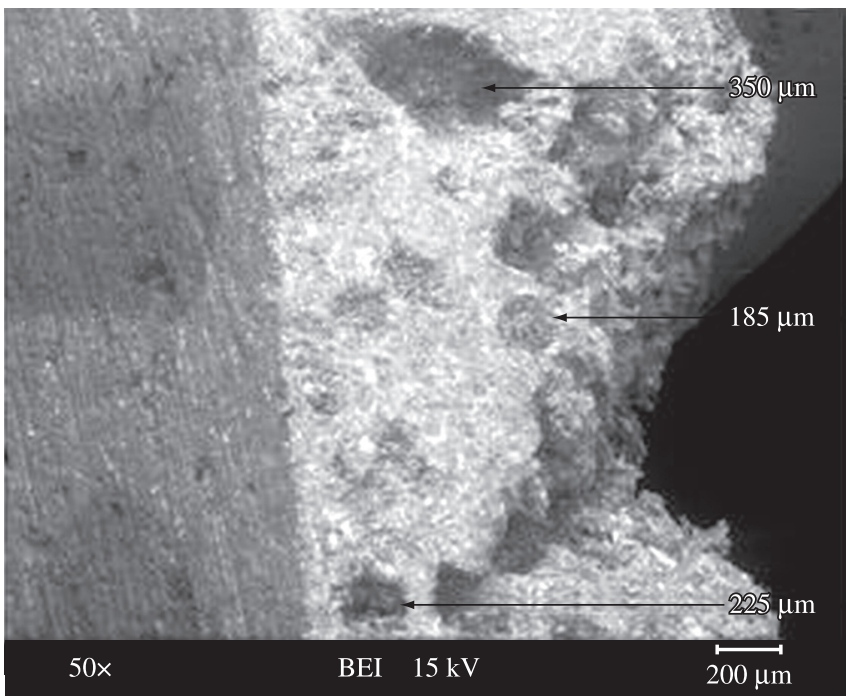

(b)

Figure 3. SEM images of grinded fracture surfaces of specimens from COOL formulation A (top) and A/2 (bottom). 


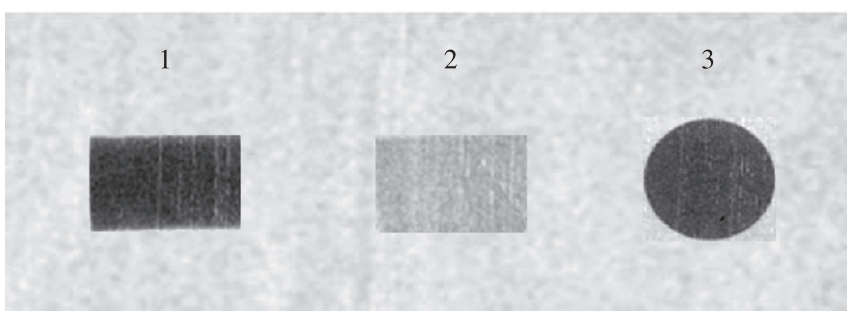

Figure 4. X-ray opacity of COOL formulation A 1) in comparison to Refobacin ${ }^{\circledast}$; 2) and titanium specimen; and 3) (exposure time 0.5 seconds).

Control

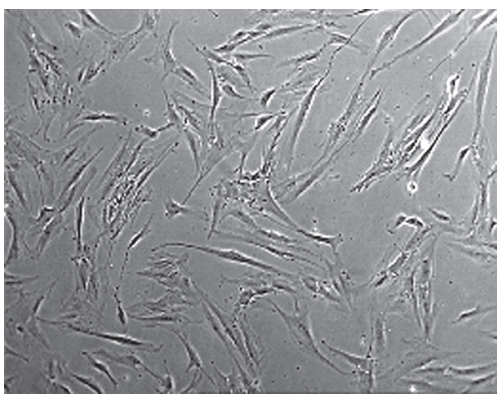

(a)

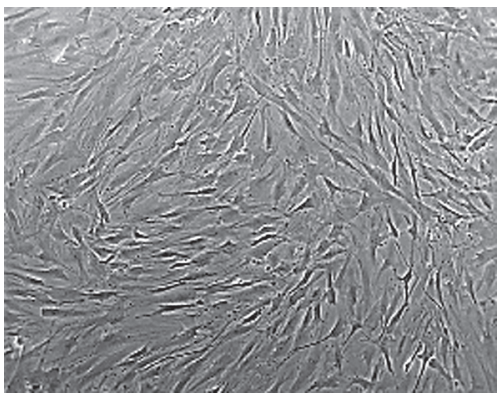

(b)

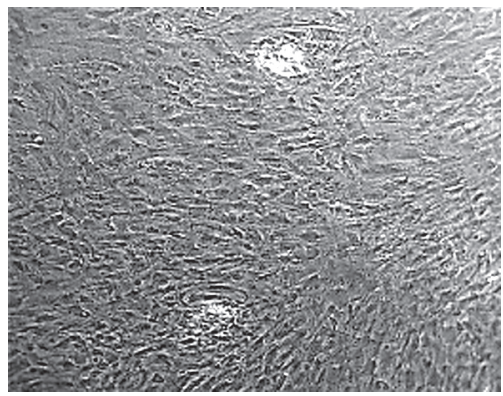

(c)
COOL (A)

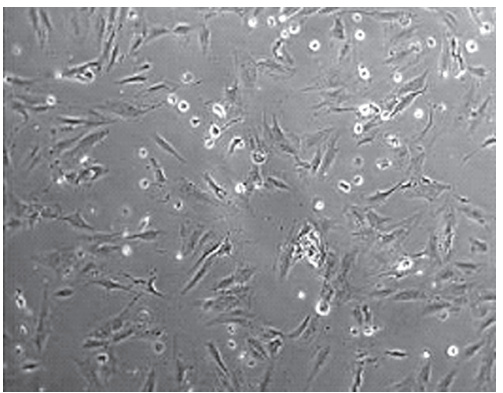

(d)

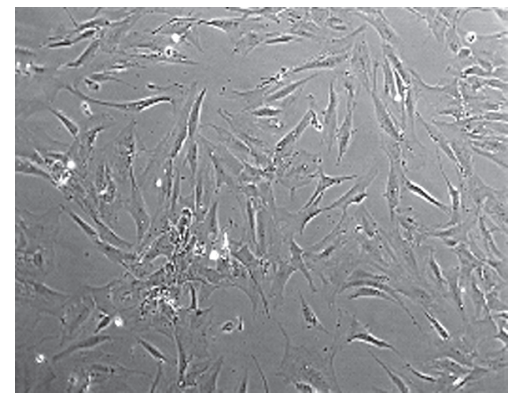

(e)

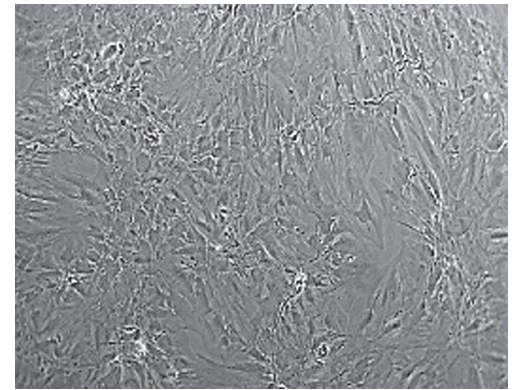

(f)
Refobacin R

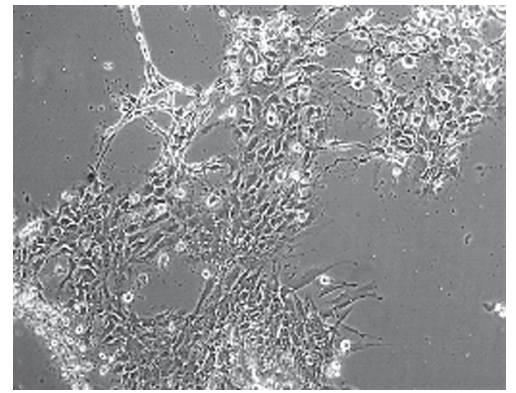

(g)

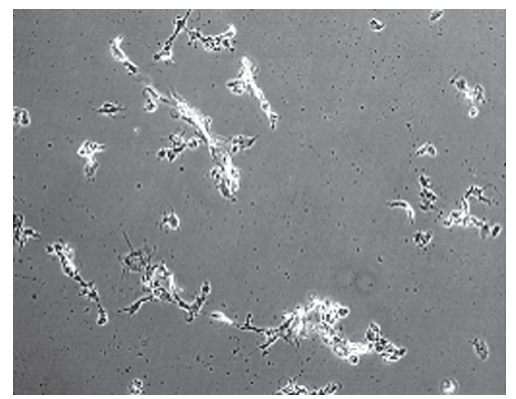

(h)

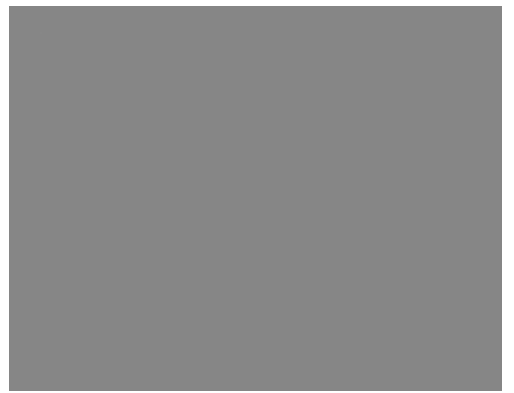

(i)

Figure 5. Light microscopic analysis of pHOB cell morphology (donor 1) during incubation with specimens of COOL formulation A (d-f) in comparison to cells of the control (a-c) and those with reference material (g-i) at day 2, 5 and 16 of culture. Bone cement specimens were added to the cell cultures immediately after preparation (magnification 100x).

FA mix. In formulations $\mathrm{C}$ to $\mathrm{E} 40 \mathrm{wt}$. (\%) of resorbable bioceramic GB14 were substituted by another ceramic component as described in Table 1 . Not any of the substitutions led to substantial differences of bending or compressive strength.

Compressive and bending strength was higher if tested after 7 and 10 days, respectively. Compressive strength increased during the first 3 days of storage in water as well as in air. Values for water stored specimens stayed constant within the following 7 days (33.2 $\pm 1.6 \mathrm{MPa})$, whereas those for air stored specimens were still increasing ( $62.8 \pm 1.3 \mathrm{MPa})$ after 10 days of storage. Bending strength increased to $26.4 \pm 1.3 \mathrm{MPa}$ if stored in air for 7 day, but decreased slightly $(18.5 \pm 3.0 \mathrm{MPa})$ if stored in water.

Reference material showed bending and compressive strength after 48 hours of $57.8 \pm 2.8 \mathrm{MPa}$ and $74.1 \pm 2.5 \mathrm{MPa}$, respectively. 


\subsection{Setting behavior of $\mathrm{COOL}$}

By mixing the viscous dissolution of modified PMMA with the mixture of bioceramics, a creamy adhesive compound is formed. Setting takes place through cementation at body temperature. A significant decrease in initial setting time was observed if $\mathrm{ZnO}$ was added to the composite. An initial setting time of 26 minutes was measured for COOL standard formulation $\mathrm{A}$. In contrast, $\mathrm{COOL}$ formulation $\mathrm{A} / 2$ lacking $\mathrm{ZnO}$ showed initial setting after 107 minutes. Reference material had an initial setting time of less than 7 minutes.

\subsection{Porosity}

Dependent on the formulation of COOL, high variation in pore sizes was observed by using SEM. All fracture surfaces showed a large amount of pores, which differed in shape and size. As an example, Figure 3 shows differences in the appearance between the breaking edges of COOL formulations containing $\mathrm{ZnO}(\mathrm{A})$ and those that lack $\mathrm{ZnO}(\mathrm{A} / 2)$. Compared to formulation $\mathrm{A}$, formulation $\mathrm{A} / 2$ clearly showed larger amounts of pores. Furthermore, pore diameters were higher in formulation $\mathrm{A} / 2$. In general, all formulations lacking $\mathrm{ZnO}$ revealed more and bigger pores compared to similar formulations containing $\mathrm{ZnO}$. Majority of the pores of all formulations were $>50 \mu \mathrm{m}$.
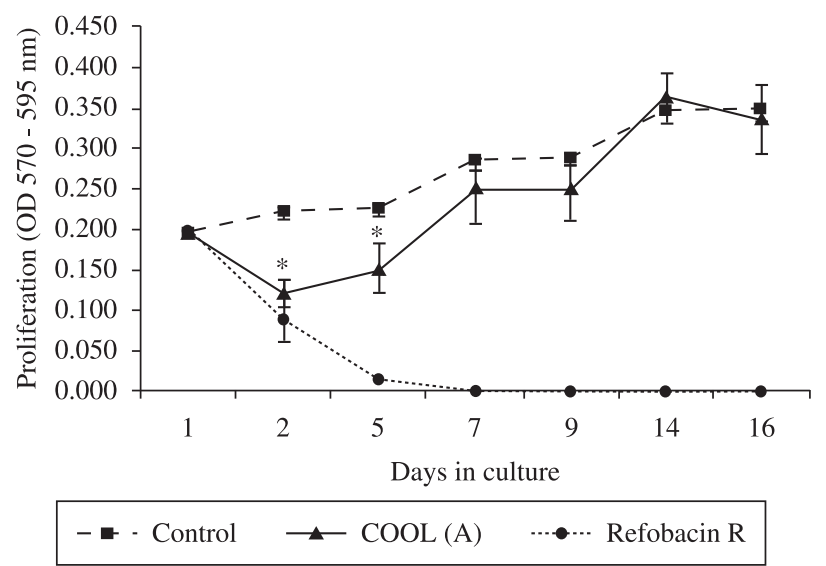

(a)

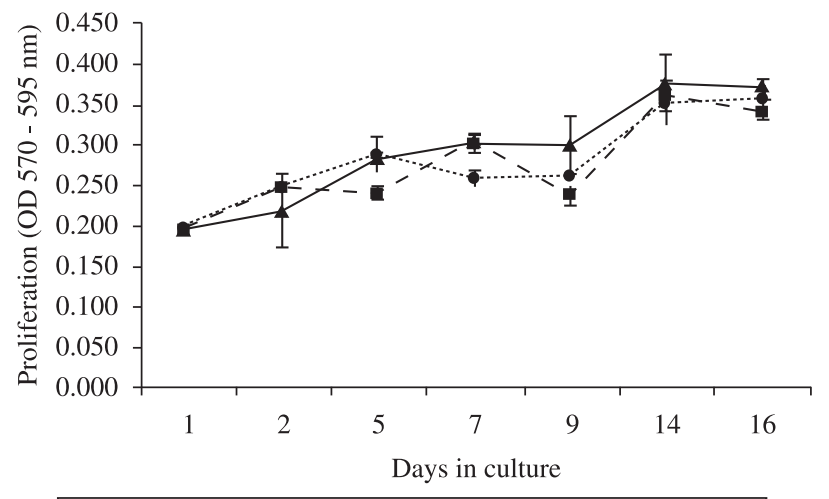

- - Control COOL (A) $\longrightarrow \cdots$ Refobacin R

(b)

Figure 6. Proliferation of $\mathrm{pHOB}$ cells derived from donor 1 incubated with COOL formulation A or reference material in comparison to the control during the entire cultivation period of 16 days. a) Cement specimens were added to the cell monolayers directly after preparation and b) 24 hours after mixing. Results are the mean $\pm S D, n=3$ ). Significant differences between COOL and reference are marked with $*(\mathrm{P}<0.05)$.
Except for formulation $\mathrm{A} / 2$, which had a porosity of $43 \%$, all other formulations (A - E) showed porosity between 31 and $37 \%$.

\subsection{X-ray opacity}

The specimens could be displayed with exposure times up to $0.5 \mathrm{sec}$. Radiopacity of COOL formulation A and titan specimen were comparatively high, whereas radiopacity of reference material was rather low (Figure 4).

\subsection{Biocompatibility of $\mathrm{COOL}$}

In contrast to Refobacin ${ }^{\circledR} \mathrm{R}$, COOL revealed high biocompatibility In Vitro independent of setting time. Figure 5 shows morphology of pHOB cell cultures from donor 1 after 2, 5 and 16 days of incubation with specimens of COOL formulation A (Figure 5d-f) or Refobacin ${ }^{\circledR} \mathrm{R}$ (Figure 5g-i) added to the cell monolayer directly after preparation. At day 2, control cells (Figure 5a) and cells of the COOL group (Figure 5d) showed typical long-stretched fibroblast-like appearance during early proliferation. Cells incubated with reference material, however, showed no fibroblast-like appearance at all (Figure $5 \mathrm{~g}$ ) and a large part of them was lost from the surface of the culture discs. Cell density intensively increased between day 2 and day 16 of culture and the pHOB cells became a polygonal shape (Figure 5a-f). At day 16, a comparatively high cell density could be observed in cultures incubated with COOL (Figure 5f) and those of the control (Figure 5c). In cultures incubated with reference material, however, all cells died after 5 days in culture (Figure 5h-i). Determination of cell viability revealed similar results. Differences in cell proliferation rates were measured between the control and cultures incubated with COOL and Refobacin ${ }^{\circledR}$ R. Cell viability slightly decreased in all these groups until day 2 (Figure 6a). Between day 5 and day 7 , cell proliferation rates rapidly increased, except for cells incubated with Refobacin ${ }^{\circledR}$ R. In this group, proliferation rapidly decreased over time, resulting in total lost of cells after 5 days in culture. In case of adding bone cement specimens after 5 hours (Figure 6b) and 24 hours (data not shown) of setting no significant differences in proliferation behavior could be determined anymore between the three different groups.

Comparable results in cell density, morphology and viability could be observed with $\mathrm{pHOB}$ cells derived from donor 2 (results not shown).

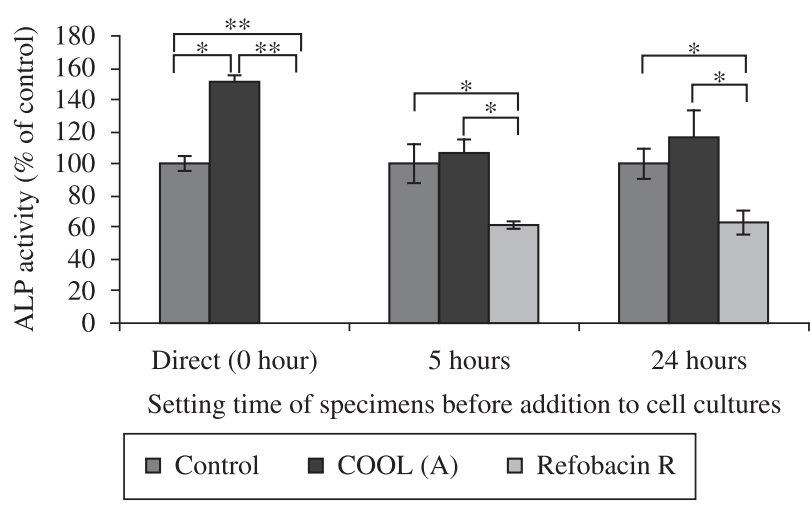

Figure 7. ALP activity in $\mathrm{pHOB}$ cell cultures derived from donor 1 incubated with specimens of COOL formulation A or reference material at day 16, calculated as percentage of the control. Cement specimens were added to the cell cultures directly after preparation ( 0 hour) and after setting for 5 or 24 hours. Results are the mean $\pm \operatorname{SD}(n=3)$. Significant differences between the groups are marked with $*(\mathrm{P}<0.05)$ or $* *(\mathrm{P}<0.01)$. 


\subsection{Osteoinductivity of COOL}

Figure 7 shows the results of ALP activity measurements at day 16 in $\mathrm{pHOB}$ cell cultures of donor 1 incubated with COOL formulation A or Refobacin ${ }^{\circledR} \mathrm{R}$ in relation to the control. Independent of setting time, ALP activity was considerably higher in cultures incubated with COOL compared to those incubated with reference material.

If added to the cultures directly after preparation, $\mathrm{pHOB}$ cells incubated with reference material died after 5 days in culture, whereas COOL cultures survived, thereby showing a 50\% higher ALP activity as cultures of the control. Compared to COOL, ALP activity was reduced by $40 \%$ in cultures incubated with Refobacin ${ }^{\circledR} \mathrm{R}$ if added to the cell monolayers after 5 hours and by nearly $60 \%$ if added after 24 hours of setting. After 5 and 24 hours of setting, however, no significant differences in ALP activity could be determined anymore between COOL and control cultures.

ALP activity measurements with $\mathrm{pHOB}$ cells derived from donor 2 revealed similar results. (data not shown).

\section{Discussion}

This study describes material properties and In Vitro biocompatibility of the novel platform technology COOL, which is a composite of biostable as well as biodegradable ceramics and dissolved, chemically modified PMMA.

Setting of COOL takes place via a cementation reaction at room or body temperature. This reduces stress to the surrounding tissue compared to PMMA based cements where high temperature of up to $110^{\circ} \mathrm{C}$ and corresponding heat necrosis were reported ${ }^{5}$. Humidity or direct contact to water or other fluids do not influence the cementation reaction of COOL. Metallic ions are integrated into the modified PMMA structure due to their high complex formation capability by interactions with free electron pairs from the carboxyl group. Bending and compressive strength of COOL can be varied in a relatively broad range by adding $\mathrm{ZnO}$ which is interesting to achieve properties needed for different indications.

COOL did not achieve bending and compressive strength as seen for classical PMMA based cements, but it should be considered that no mechanical mixing system was applied. It should also be considered that if standard PMMA based cements were in contact with blood during polymerization, bending strength would be reduced to less than $25 \mathrm{MPa}^{25}$. This raises the question if current test methods (ISO 5833) are suitable to predict mechanical strength in vivo and whether 25 instead of $50 \mathrm{MPa}$ bending strength would also be sufficient for fixation of hip joint prostheses.

Compared to PMMA based cements mechanical strength of CPCs is weaker. Depending on the composition final compressive strength can vary at a large scale between 4 and $80 \mathrm{MPa}$. Moreover, CPCs possess high brittleness and low bending strength ${ }^{7}$ which was not observed for COOL with a bending strength of up to 26.4 MPa.

Dependent on the field of application resorption of cements within different time frames and to a different extent is desirable. COOL is partially resorbable. Extent and timeframe are dependent on the ceramic components. Since the mechanical properties of different formulations are comparable, resorption time can be varied by changing proportions of fast resorbable (GB14), slow resorbable (TETRA) and biostable (CZP/FA) bioceramics ${ }^{26}$. In order to achieve good resorption and ingrowth of cells into bone cements, porosity and a minimum pore size are required. The porosity of COOL is between 31 and $37 \%$ which is less than the range described for $\mathrm{CPCs}^{27}, 40$ to $60 \%$. Healing of large bone defects requieres macro pores $(>50 \mu \mathrm{m})$ to enable initial ingrowth of bone cells into the artificial material followed by its resorption and substitution by newly generated bone in a moderate time interval. Classical CPCs like Norian SRS have pores with a diameter of $30 \mathrm{~nm}$. COOL shows a mixture of micro and macro pores with a diameter of up to $350 \mu \mathrm{m}$ which render the possibility of ingrowths of osteoblasts. Effects of these large pores and combination of the different bioceramics on resorption behavior of COOL have to be investigated more extensively In Vitro and in vivo.

In orthopedic surgery bone cement application usually proceeds within a time span of up to 10 minutes after mixing. Large defects and revision of position need more time. Therefore longer setting times might be mandatory as well. In vertebroplasty, longer setting times are preferential in order to ensure optimal filling of the vertebral body. Setting times between 1 (4) and > 20 (17) minutes are reported for standard CPCs (PMMA) ${ }^{5}$. COOL possesses a setting time of 20 minutes which can be prolonged by changes in the composition. The latter is favorable for e.g. vertebroplasty in agreement with Chavali et al. ${ }^{28}$ who used ice cooling to prolong the application time and to delay the polymerization reaction. In other cases, faster setting can be beneficial requiering further investigations on the composition of COOL.

Obviously during application, the cement has not yet completely hardened, which may provoke adverse biological effects associated with the reaction mechanism as found for PMMA cements ${ }^{5,29}$. So, for testing biocompatibility of new biomaterials to bone cells In Vitro, it is important to use a method that matches the in vivo situation as closely as possible. For that reason, in this study In Vitro biocompatibility of COOL was determined in $\mathrm{pHOB}$ cells at different time points after mixing. Except for some small donor-dependent variations, no cytotoxic effects on $\mathrm{pHOB}$ cell density, morphology and viability could be observed during incubation with COOL formulation A independent on the setting time. In accordance to Siggelkow et al. ${ }^{30}$, pHOB cells from both donors showed a typical long-stretched fibroblast-like appearance during early proliferation, which switched to polygonal during continuing proliferation. In contrast, $\mathrm{pHOB}$ cells incubated with Refobacin ${ }^{\circledR} \mathrm{R}$ added to the cultures directly after preparation showed extremely high death rates, probably due to chemical necroses caused by the release of free, not polymerized, toxic MMA monomers.

However, differences in cell density, morphology and viability between cultures incubated with COOL or Refobacin ${ }^{\circledR} \mathrm{R}$ disappeared completely when the specimens were added 5 or $24 \mathrm{~h}$ after mixing, respectively. These results confirm the findings of another group, which analyzed cell proliferation of various acrylic bone cements added at different time intervals after polymerization ${ }^{31,32}$. They found that cytotoxic effects of these cements are inversely proportional to their polymerization time, which means that toxicity of PMMA-based cements decreases with proceeding polymerization time. In the future, adaption of the general test system should be considered in order to resemble the in vivo situation more closely.

COOL revealed significant higher ALP activity even when viability was comparable indicating that COOL has osteoinductive properties compared to Refobacin ${ }^{\circledR} \mathrm{R}$.

GB14, one of the bioceramics used, conveys cells to adhere to the biomaterial based on the mechanism described by Knabe and Berger $^{33}$. So, GB14 strongly contributes to the osteoconductive properties of COOL.

Another component of the ceramic mixture is $\mathrm{CZP}$, which is biostable ${ }^{2,30}$ and increases the radiopacity of COOL. It accounts for less than $10 \mathrm{wt}$. (\%) and is well integrated into the PMMA matrix. In all In Vitro studies independent of application time, COOL reached at least cell viability and ALP activity comparable to control. CZP is generally described as biocompatible proven in In Vitro as well as in in vivo studies ${ }^{34}$. Only recently, CZP coated implants were found to reduce bone mineralization in vivo ${ }^{35}$. Since a special thermal treatment (flame spray) was applied during the coating process, these findings can neither be generalized nor assigned to COOL. 
$\mathrm{ZnO}$ is an important component of COOL, since it increases the mechanical properties. Zinc is an essential element and plays an important role in bone metabolism ${ }^{36}$. Zinc deficiency can lead to reduced levels of alkaline phosphatase (ALP) activity in bone ${ }^{37,38}$ which results in reduced bone formation. Another positive feature of zinc is, that it works antiseptically ${ }^{39,40}$. The effects are a question of the concentration used since at higher concentrations of Zinc powder it was found to be cytotoxic somehow ${ }^{41,42}$. The amounts of $\mathrm{ZnO}$ used in the COOL formulations did not have any negative effect on biocompatibility as shown. Taken together with the rationale that $\mathrm{Zn}$ ions are integrated into the PMMA matrix no negative effects are expected for COOL, but further studies sought to be carried out.

Although COOL did not reach the bending and compressive strength for endoprosthetic applications according to ISO 5833, stability and toughness of healthy spongy and trabecular bone were achieved. Lower bending and compressive strength might even be a possibility to reduce stress between implant and bone. In case the powder-liquid ratio of PMMA based cements were changed, a reduction of strength up to $24 \%$ would be caused without any remarkable influence on the patient outcome ${ }^{28}$. High radiopacity, good biocompatibility, compressive and bending strength of $>20 \mathrm{MPa}$ are warranted for vertebroplasty ${ }^{5,43}$ and can be provided by COOL.

\section{Conclusion}

In conclusion, COOL demonstrates good mechanical properties and high biocompatibility In Vitro. COOL presents a good balance between porosity and pore size on the one hand and mechanical properties on the other hand and reaches bending and compressive strength comparable to trabecular bone. In contrast to traditional PMMA cements, COOL exhibits less mechanical strength, but cures at body temperature. It releases components of bioceramics, exhibits macropores for ingrowth of osteoblasts and has high radiopacity. In contrast to CPCs, COOL possesses higher bending strength which improves the applicability, is $\mathrm{pH}$-neutral and water stable. Overall COOL should be further investigated in different in vivo models for different applications areas such as endoprosthetics and vertebroplasty.

\section{Acknowledgements}

We thank Dr. G. Berger from Federal Inst. of Research Berlin for delivering the ceramics.

\section{References}

1. Charnley J. Surgery of the hip-joint: present and future developments. British Medical Journal. 1960; 1(5176):821-826.

2. Charnley J. The reaction of bone to self-curing acrylic cement: a longterm histological study in man. Journal of Bone and Joint Surgery. 1970; 52(2):340-353.

3. Kühn KD. Bone cements: up-to-date comparison of physical and chemical properties of commercial materials. Berlin: Springer-Verlag; 2000.

4. Gross AE. The role of polymethylmethacrylate bone cement in revision arthroplasty of the hip. Orthopedic Clinics of North America. 2005; 36(1):49-54.

5. Webb JC and Spencer RF. The role of polymethylmethacrylate bone cement in modern orthopaedic surgery. Journal of Bone and Joint Surgery. 2007; 89(7):851-857.

6 .Brook IM and Hatton PV. Glass-ionomers: bioactive implant materials. Biomaterials. 1998; 19(6): 565-571.

7. Ambard AJ and Mueninghoff L. Calcium phosphate cement: review of mechanical and biological properties. Journal of Prosthodontics. 2006; 15(5):321-328
8. LeGeros RZ. Properties of osteoconductive biomaterials: calcium phosphates. Clinical Orthopaedics and Related Research. 2002; (395):81-98.

9. Glant TT, Jacobs JJ, Mikecz K, Yao J, Chubinskaja S, Williams JM, Urban RL, Shanbhag AS, Lee So and Sumner DR. Particulate-induced, prostaglandin- and cytokine-mediated bone resorption in an experimental system and in failed joint replacements. American Journal of Therapeutics. 1996; 3(1):27-41.

10. Mjöberg B, Pettersson H, Rosenqvist R and Rydholm A. Bone cement, thermal injury and the radiolucent zone. Acta Orthopaedica Scandinavica. 1984; 55(6):597-600.

11. Deramond H, Wright NT and Belkoff SM. Temperature elevation caused by bone cement polymerization during vertebroplasty. Bone. 1999. 25(Suppl. 2):17S-21S.

12. Eggert A, Huland H, Ruhnke $J$ and Seidel H. Penetration of methylmethacrylate-monomer in blood circulation following hip joint prosthesis surgery in man. Chirurg. 1974. 45(5):236-242.

13. Gough JE and Downes S, Osteoblast cell death on methacrylate polymers involves apoptosis. Journal of Biomedical Materials Research. 2001; 57(4): 497-505.

14. Liso PA, Vázquez B, Rebuelta M, Hernáez ML, Rotger R and Román JS. Analysis of the leaching and toxicity of new amine activators for the curing of acrylic bone cements and composites. Biomaterials. 1997; 18(1):15-20.

15. Arola D, Stoffel KA and Yang DT. Fatigue of the cement/bone interface: the surface texture of bone and loosening. Journal of Biomedical Materials Research Part B: Applied Biomaterials. 2006; 76(2):287-297.

16. Puska MA, Lassila LV, Närhi TO, Yli-Urpo AUO and Vallittu PK. Mechanical properties of oligomer-modified acrylic bone cement. Biomaterials. 2003; 24(3):417-425.

17. Currey JD. Bones: structure and mechanics. Princeton: Princeton University Press; 2002.

18. Ohtsuki C, Kamitakahara M and Miyazaki T. Coating bone-like apatite onto organic substrates using solutions mimicking body fluid. Journal of Tissue Engineering and Regenerative Medicine. 2007; 1(1):33-38.

19. Yang JM. Study of polymerization of acrylic bone cement: effect of HEMA and EGDMA. Journal of Biomedical Materials Research. 1998; 43(1):54-61.

20. Abdel-Kader KF, Allcock S, Walker DI and Chaudhry SB. Boneloc bonecement: experience in hip arthroplasty during a 3-year period. Journal of Arthroplasty. 2001; 16(7):811-819.

21. Mueller WD, Berger G and Nagel E. Method for producing a bioactive bone cement and bone cement kit. 2005; EP 1395296 B1

22. Berger G, Gildenhaar R and Ploska U. Rapid resorbable, glassy crystalline materials on the basis of calcium alkali orthophosphates. Biomaterials. 1995; 16(16): 1241-1248.

23. Knabe C, Berger G, Gildenhaar R, Meyer J, Howlett CR, Markovic B and Zreiqat $\mathrm{H}$. Effect of rapidly resorbable calcium phosphates and a calcium phosphate bone cement on the expression of bone-related genes and proteins in vitro. Journal of Biomedical Materials Research. 2004; 69A(1): 145-154

24. Ploska $U$ and Berger G. Solubility of compositions in the system CaTi(x) Zr4-(x)(PO4)6 with $\mathrm{x}=0-4$. Biomaterials. 1997; 18(24):1671-1675.

25. Gravius S, Wirtz DC, Marx R, Maus U, Andereya S, Müller-Rath R and Mumme T. Mechanical in vitro testing of fifteen commercial bone cements based on polymethylmethacrylate. Zeitschrift für Orthopädie und Unfallchirurgie. 2007; 145(5):579-585.

26. Knabe C, Berger G, Gildenhaar R, Howlett CR, Markovic B and Zreiqat $\mathrm{H}$. The functional expression of human bone-derived cells grown on rapidly resorbable calcium phosphate ceramics. Biomaterials. 2004. 25(2):335-344.

27. Kenny SM and Buggy M. Bone cements and fillers: a review. Journal of Materials Science: Materials in Medicine. 2003; 14(11):923-938.

28. Chavali R, Resijek R, Knight SK and In-Sup C. Extending polymerization time of polymethylmeth acrylate cement in percutaneous vertebroplasty 
with ice bath cooling. American Society of Neuroradiology. 2003; 24(3):545-546.

29. Feith R. Side-effects of acrylic cement implanted into bone. A histologicl, (micro)angiographic, fluorescence-microscopic and autoradiog-aphic study in the rabbit femur. Acta Orthopaedica Scandinavica. 1975; 161(Suppl.):3-136.

30. Siggelkow H, Rebenstorff K, Kurre W, Niedhart C, Engel I, Schulz H, Atkinson MJ and Hüfner M. Development of the osteoblast phenotype in primary human osteoblasts in culture: comparison with rat calvarial cells in osteoblast differentiation. Journal of Cellular Biochemistry. 1999; 75(1):22-35.

31. Granchi D, Stea S, Ciapetti G, Cavedagna D, Stea S and Pizzoferrato A. Endodontic cements induce alterations in the cell cycle of in vitro cultured osteoblasts. Oral Surgery, Oral Medicine, Oral Pathology, Oral Radiology \& Endodontics. 1995; 79(3):359-366.

32. Ciapetti G, Granchi D, Stea S, Cervellati M, Pizzoferrato A and Toni A. In vitro testing of ten bone cements after different time intervals from polymerization. Journal of Biomaterials Science: Polymer Edition. 2000; 11(5):481-493.

33. Knabe C, Ostapowicz W, Radlanski RJ, Gildenhaar R, Berger G, Fitzner $\mathrm{R}$ and Gross $\mathrm{U}$. In vitro investigation of novel calcium phosphates using osteogenic cultures. Journal of Materials Science: Materials in Medicine 1998; 9(6):337-345.

34. Knabe C, Berger G, Gildenhaar R, Klar F and Zreiqat $\mathrm{H}$. The modulation of osteogenesis in vitro by calcium titanium phosphate coatings. Biomaterials. 2004. 25(20):4911-4919.

35. Bernstein A, Nobel D, Mayr HO, Gobel F, Berger G, Ploska U, Gildenhaar R and Brandt J. Inhibition of mineralization by a calcium zirconium phosphate coating. Journal of Biomedical Materials Research Part B: Applied Biomaterials. 2008; 86B(2):422-429.

36. Dimai HP, Hall SL, Stilt SB and Farley JR. Skeletal response to dietary zinc in adult female mice. Calcified Tissue International. 1998; 62(4):309-315.

37. Mattioli-Belmonte M, Mengucci P, Specchia N, Gobbi G, Dubini S, Simonelli L, Greco F, Majni G, Biagini G and Rizzoli C. An experimental study in X-ray spectroscopy of the zirconium (Ca-PSZ) bone interface: microanalytic evaluation of the osteogenetic response. Journal of Materials Science: Materials in Medicine. 1997; 8(2):85-90.

38. Charnley J. Proceedings: the histology of loosening between acrylic cement and bone. Journal of Bone and Joint Surgery. 1975; 57(2):245.

39. Towler MR, Kenny S, Boyd D, Pembroke T, Buggy M and Hill RG. Zinc ion release from novel hard tissue biomaterials. Bio-medical Materials and Engineering. 2004; 14(4):565-572.

40. Towler MR, Kenny S, Boyd D, Pembroke T, Buggy M, Guida A and Hill RG. Calcium and zinc ion release from polyalkenoate cements formed from zinc oxide/apatite mixtures. Journal of Materials Science: Materials in Medicine. 2006; 17(9):835-839.

41. Yamaguchi M, Oishi H and Suketa Y. Zinc stimulation of bone protein synthesis in tissue culture: activation of aminoacyl-tRNA synthetase. Biochemical Pharmacology. 1988. 37(21):4075-4080.

42. Yamaguchi M, Oishi H and Suketa Y. Stimulatory effect of zinc on bone formation in tissue culture. Biochemical Pharmacology. 1987; 36(22):4007-4012.

43. Blattert TR, Delling G and Weckbach A. Evaluation of an injectable calcium phosphate cement as an autograft substitute for transpedicular lumbar interbody fusion: a controlled, prospective study in the sheep model. European Spine Journal. 2003; 12(2):216-223. 